\title{
Supported Relationships to Support the Rocking Ship
}

\author{
Santosh K. Chaturvedi
}

Received: 4 October 2021 / Accepted: 4 October 2021/Published online: 13 October 2021

(C) The Author(s), under exclusive licence to Springer Nature India Private Limited 2021

In this special issue of the Journal of Psychosocial Rehabilitation and Mental Health, we have focused on supported services for persons with mental health problems to help them in their recovery and rehabilitation. There is enough literature on the role of supported employment, supported housing and supported education as and when required to help in the recovery of persons with chronic mental illnesses. In fact, for too long, psychosocial rehabilitation meant only vocational rehabilitation and supported employment. Other areas of mental disability are related to personal, marital, and family life. One wonders if similar concept of supported services can be applied to supported relationships. Like any ship may rock in turbulent waters, 'relation-ships' can sway out of control.

Supported relationships would mean helping an individual with mental health problems or disability to engage in having a partner or friend or a spouse or a live-in relationship or similar person. The mental health professionals and services could help in providing support and encouragement to develop this relationship in the same way as supported employment helps in 'place and train' concept instead of the traditional 'train and place' and supported education provides continuous support to the person while they

S. K. Chaturvedi $(\square)$

Leicestershire Partnership NHS Trust, Leicester, UK

e-mail: skchatur@gmail.com pursue their education. Support may be provided for dating or developing friendships and joining or forming peer groups. It is difficult to speculate on the impact of such interventions; of course, caution and support is required at every step, including how to cope with break ups, heart breaks and similar events.

Families are invariably concerned about marriage of their patient with mental illness, due to stigma, and even disability. Marital alliance websites do not encourage persons with mental illness. I have heard of, ManoMatrimony, a matchmaking site that helps those with mental illnesses to find a life partner. The website was developed with a view to helping the patients declare their mental illnesses before they settle for a match. It is a little different from other numerous matrimonial websites where only the families concerned decides the fate of the alliance. For Manomatrimony, it seems applicants have to register online, but with the certification from their psychiatrist, and have to make a complete disclosure of their medical history, including handicaps. With initiatives like ManoMatrimony or manomarriage.com, we can hope that the stigma about mental illness is gradually reduced. There are special columns in matrimony websites for divyangs, physically, mentally special able people, visual, hearing and speech disabled people. In supported relationships, one hopes professionals and support workers will go beyond matrimony and focus on quality of relationships. 
Supported parenting could be an extension of this concept. Supported parenting could be a way to help persons with mental illness have a family, and be able to support, both the parents, mother, and/or father. One hopes these activities are tried and tested, become popular and useful, and supported by research evidence. Most supported activities are likely to be dynamic and change with time and development of technology and society.

Considering the importance of supported activities for recovery and rehabilitation, this special issue is dedicated to articles on this topic. Drs Nagesh Pai, David Castle and Frances Dark, all from Australia, have edited this issue with diligence, and stress on the importance of employment in recovery of persons with severe mental illness. They hope that the articles assembled in this Special Edition give some indications to the field as to some of the effective interventions that have helped people with schizophrenia and related disorders obtain and retain work.

This issue has good international representation with three articles from the USA namely, improving healthcare access and utilization among student veterans through supported education; Assertive Community Treatment Collaboration with Community Medical Providers; and Rasch Analysis of the Behavioral Assessment Screening Tool (BAST) in Chronic Traumatic Brain Injury. There are two articles from Australia, First Person Account of Returning to
Education and Competitive Employment Following Serious Mental Illness and Improving Cognitive Skills for People with Mental Illness to Increase Vocational and Psychosocial Outcomes: The Employ Your Mind Program. There are also three articles from Canada, namely, Assertive Community Treatment Collaboration with Community Medical Providers, Real-World Uptake of Supported Employment and Education in the First 3 Months of Early Psychosis Intervention Services. There are two articles from Norway-Resist or Adapt? A Narrative Analysis of Endeavours for Belonging Among Young Adults with Co-Occurring Substance Use and Mental Health Problems and Securing Participant Engagement in Longitudinal Substance Use Disorder Recovery Research: A Qualitative Exploration of Key Retention Factors. One each from India, Family Reintegration of a Homeless Person through Case Management Approach from India, and Brazil, Promoting Citizenship and Access to the Right to Health: a Look of Caregivers. Lastly, there is an interesting book review on a sensitive subject of suicide of a partner, dealt with poignantly in the most touching book- Left Behind: Surviving Suicide Loss by Nandini Murali, review written by a resident psychiatrist.

With the pandemic waning, hopefully forever, one hopes supported services would become face-to-face, in person, like ancient times, and use remote and virtual methods only when needed. 